\title{
Modelling the Effect of Temperature on Respiration Rate of Fresh Cut Papaya (Carica papaya L.) Fruits.
}

\begin{abstract}
A respiration rate (RR) model based on Peleg's equation was developed for predicting RRs of fresh cut papaya. Respiration data for fresh cut papaya at 3/4 maturity were generated at temperatures $5,10,15,20,25$ and $30^{\circ} \mathrm{C}$ using a closed system. RRs was found to be significantly influenced by storage temperature and increased from 0.021 to 0.289 $\mathrm{mL}[\mathrm{O} 2] / \mathrm{kg} \cdot \mathrm{h}$ and 0.063 to $0.393 \mathrm{~mL}[\mathrm{CO} 2] / \mathrm{kg} \cdot \mathrm{h}$ as a function of $\mathrm{O} 2$ and $\mathrm{CO} 2$ gas concentrations, respectively. Peleg's constant $\mathrm{K} 1$ and $\mathrm{K} 2$ were obtained from linear regression analysis using GraphPad Prism 5.0 software and regression coefficients have good fit with values close to unity. The model was verified to assess the capability of its predictability of the RRs over the temperatures. There was good agreement with the experimentally estimated RRs. Information derived from the model can contribute in the design of successful modified atmospheric systems for storage of fresh cut papaya.
\end{abstract}

Keyword: modelling, respiration rate, temperature, papaya, Peleg`s model 